\title{
Atores, AÇões e dominaÇão CUltural NA CONSTRUÇÃO DA INDÚSTRIA DE CAPITAL DE RISCO NO BRASIL
}

\author{
Martin MUNDO NETO* \\ Patricia SALTORATO*
}

\begin{abstract}
RESUMO: Este artigo aborda a indústria brasileira de capital de risco a partir da trajetória dos agentes que contribuíram para seu desenvolvimento. O Estado desempenhou um papel importante na regulamentação dessa indústria, notadamente a partir da criação da Comissão de Valores Mobiliários (CVM), da Financiadora de Estudos e Projetos (FINEP) e da BNDESPar, subsidiária do Banco Nacional de Desenvolvimento Econômico e Social (BNDES). O artigo conclui que, apesar da legitimidade desta indústria estar ligada ao financiamento da inovação tecnológica pelas firmas gestoras que atuam junto ao segmento venture capital, aqueles que dominam culturalmente a indústria, preferem investir no segmento private equity, onde o retorno sobre o investimento é significativamente maior e o risco, menor. Como resultado, os dados extraídos da CVM, indicam que, o financiamento via venture capital, onde a incerteza e os riscos são mais elevados, recaem principalmente sobre as agências governamentais, reproduzindo a dominação cultural predominante na indústria mundial.
\end{abstract}

PALAVRAS CHAVE: Financeirização. Fundos de investimentos. Capital de risco. Sociologia econômica.

FATEC-Faculdade de Tecnologia de Taquaritinga. Taquaritinga-SP, Brasil. 15900000 - martin.neto@ fatectq.edu.br.

* UFSCar-Universidade Federal de São Carlos. Campus Sorocaba. Sorocaba-SP, Brasil. 18052780 patriciasaltorato@gmail.com. 


\section{Introdução}

Nos últimos anos, o mercado financeiro brasileiro ganhou uma relevância inédita na economia do país, que, longe de ser uma particularidade tupiniquim, faz parte de um processo em curso no capitalismo contemporâneo conhecido como financeirização (DAVIS; KIM, 2015). Esse processo engendrou a partir da década de 1980; a emergência, ascensão e o crescente poderio de um grupo de atores do espaço das finanças; os gestores de fundos private equity $(\mathrm{PE})$ com variadas implicações para estados, empresas e indivíduos. Tidos como intermediários financeiros (GRÜN, 2013; FROUD; WILLIAMS, 2007, APPELBAUM; BATT, 2014), estes atores passaram a fomentar um mecanismo de investimento/financiamento alternativo ao sistema bancário tradicional. Porém, mais que uma mera alternativa de investimento, estes atores legitimaram junto aos market-makers actors, um conjunto de valores, crenças, mitos e ritos exercendo uma dominação cultural, no sentido empregado por DiMaggio (2001), relativa à atuação na indústria de capital de risco.

A atuação desses atores envolve, em linhas gerais, o levantamento de capital junto a investidores institucionais e individuais para a formação de um fundo PE visando seu investimento em empresas cujos retornos financeiros sejam superiores àqueles obtidos a partir de outras oportunidades disponíveis (APPELBAUM; BATT, 2014; MEIRELLES et al., 2008). A participação acionária de um fundo PE em uma empresa-alvo pode chegar a $100 \%$ e ser alcançada por meio de uma aquisição hostil (takeover) ou não. A decisão sobre como participar da gestão da empresa adquirida/investida cabe aos gestores do fundo PE e pode variar desde uma; diária, intensa e agressiva até uma restrita ao conselho de administração da mesma, assim como a decisão de manter (ou não) os executivos da mesma após a aquisição (SALTORATO; BENATTI, 2017). Em relação à saída do investimento, depois de um período de tempo pré-estabelecido em contrato junto aos investidores (geralmente menos de 10 anos) esses intermediários podem vender a participação do fundo (inclusive para outros fundos) ou abrirem o capital das empresas investidas. Assim, estes intermediários contribuem tanto para incrementar as operações de Fusões \&Aquisições (F\&A) entre empresas, como para ampliar a dependência das mesmas em relação ao mercado financeiro, como para legitimar um modus operandi, exercendo uma dominação cultural sobre os atores do campo.

DiMaggio (2001, p. 167), articulando questões ligadas à racionalidade econômica, à eficiência das empresas, à origem das preferências e suas relações com diferentes níveis do que se considera cultura, ou seja, questões ligadas "à cognição social, ao conteúdo e às categorias do pensamento consciente e a tudo aquilo que tomamos por certo", conclui que o comportamento econômico está enraizado na cultura. Tal enraizamento é percebido desde um nível mais amplo do que se 
entende por cultura, associado às regras, atitudes e normas, passando pela lógica dos agentes, pelas crenças que orientam as estratégias, até os sistemas de classificação e categorização que definem objetos de pensamentos. Em outras palavras, as estruturas cognitivas condicionam e são condicionadas pelas instituições de mercado.

A maior integração da economia brasileira à mundial, a partir da década de 1990, ocorre, sobretudo por meio do fortalecimento do mercado de capitais e da dominação cultural que orienta sua organização, destacando entre essas: a privatização de estatais de energia e telecomunicações; a abertura comercial e a desregulamentação de mercados controlados pelo Estado; o aumento crescente de operações F\&A entre empresas com participação de investidores estrangeiros; as alterações na lei das sociedades anônimas e a criação do Novo Mercado da Bolsa de Valores de São Paulo, visando ao fortalecimento e à estruturação das empresas como uma sociedade por ações reproduzindo a concepção de controle baseada na cultura Shareholder Value (SHV) ou na valorização do acionista (USEEM, 1996; FLIGSTEIN, 2001), da qual as gestoras de fundos PE, apesar de menos evidentes no processo de financeirização, são representantes emblemáticas.

Considerando o exposto, este artigo explora a consolidação da indústria de capital de risco nacional, por meio das trajetórias dos atores melhor posicionados no campo; do Estado; e das relações tecidas entre eles e, destacando a estreita relação entre a esfera pública e a privada na construção social dos mercados. Em relação à metodologia de pesquisa, este trabalho empregou a pesquisa bibliográfica, documental e a imprensa de negócios, relativa aos atores-chave do campo: a Comissão de Valores Mobiliários (CVM); a Associação Brasileira de Private Equity \& Venture Capital (ABVCAP); a Agência Brasileira de Desenvolvimento Industrial (ABDI); e o Banco Garantia precursor daquelas que se tornaram referência nacional (e internacional) da atuação de fundos PE, a GP Investimentos, e a $3 \mathrm{G}$ Capital, símbolos da dominação cultural na indústria de capital de risco nacional por fundos PE.

\section{O Público e o Privado no Capital de Risco}

Historicamente, a indústria de capital de risco engloba dois segmentos com trajetórias distintas, mas que cada vez mais têm sido tratados pelas lideranças da indústria como uma unidade (ABDI, 2011). O primeiro, denominado venture capital (VC), é um segmento que opera como uma espécie de mito fundador da indústria, uma vez que os recursos ali aportados têm como destino as empresas que se encontram nos estágios iniciais de desenvolvimento, posicionadas em setores de alta tecnologia, com enorme potencial de crescimento e geração de lucro para 
os investidores. A ampliação da oferta e popularização de novas tecnologias que proporcionariam benefícios para a sociedade como um todo seria a contrapartida para as ações dos gestores dos fundos de investimentos e, ao mesmo tempo, sua fonte de legitimidade. O outro segmento do capital de risco é denominado private equity (PE). Nele estariam os investimentos destinados a grandes empresas consolidadas, na maior parte das vezes envolvendo operações de F\&A entre essas empresas (e menores riscos).

O entendimento de que a inovação tecnológica é uma das principais forças transformadoras da sociedade em geral, e da economia em particular, tem legitimado o seu financiamento (MAZZUCATO, 2013). Neste aspecto a indústria de capital de risco se insere no conjunto de políticas voltadas para o desenvolvimento econômico e, portanto, na discussão sobre qual deve ser o posicionamento do Estado na economia. Para aqueles que seguem à ortodoxia econômica, em particular os representantes da Teoria da Agência (JENSEN; MECKLING, 1976) a indústria de capital de risco seria um subespaço de vanguarda, uma vez que, nele estariam concentrados os negócios com possibilidades de gerar retornos entre os mais altos do capitalismo contemporâneo, desde que controlados os problemas de assimetria de informação entre os envolvidos. Já para quem defende uma orientação mais interventora do Estado na economia, o apoio à indústria de capital de risco decorre, em grande medida, do entendimento de que o incentivo à inovação tecnológica é essencial para o crescimento econômico e ao desenvolvimento sustentável (ARBIX, 2010; MAZZUCATO, 2013); ou, uma das formas de ampliar as capacidades estatais, na construção de um Estado desenvolvimentista, segundo as contribuições da abordagem institucionalista do Estado (DINIZ, 2013).

Mazzucato (2013) sugere uma orientação na economia que combine a necessidade de intervenção do Estado nos momentos de crise econômica, de inspiração Keynesiana, com os investimentos em inovação schumpeterianos. A autora procura desconstruir mitos associados à polarização entre público $\mathrm{x}$ privado, analisando o papel dos diferentes agentes no desenvolvimento de novas tecnologias. Segundo a autora, considerando o caso estadunidense, haveria uma divisão assimétrica dos riscos e dos resultados entre os agentes públicos e privados envolvidos na indústria de capital de risco. O Estado se ocupa dos investimentos iniciais, quando há incerteza e maior risco, tanto fornecendo infraestrutura e recursos humanos disponíveis na rede de instituições públicas de ciência e tecnologia, mas também, por meio de políticas especificas para fomentar a criação de produtos e serviços inovadores, contribuindo para o financiamento das empresas que surgem de pesquisas em universidade e centros de pesquisas, as spin offs acadêmicas. Numa fase posterior quando as incertezas acerca da tecnologia e os riscos são menores (e as taxas de retorno, maiores) o capital privado ingressa 
com mais intensidade e o Estado raramente tem participação suficiente para repor os recursos investidos.

Bourdieu (2005) indica como as ações governamentais são determinantes na organização dos mercados, pois o mesmo é responsável por criar as categorias de pensamento válidas, princípios de classificação naturalizados que ordenam a sociedade. O autor analisa as origens do Estado e sua importância para a estruturação da sociedade contemporânea, mesmo no espaço mais privado que se possa imaginar. Segundo o autor, a produção estatística pelo Estado, através, por exemplo, do recenseamento "constrói os princípios de divisão legítimos, princípios de divisão tão evidentes que não são objetos de discussão" (BOURDIEU, 2005, p.38). Assim, o autor afirma sobre a oposição entre público x privado, que "o que se chama de privado é, em grande parte, habitado pelo público, em especial a empresa. Poderia mesmo dizer mais: pensando bem, não há privado." (BOURDIEU, 2005, p.401). Ele ainda sugere que o mercado seja estudado como um campo de disputa entre dominantes e dominados, que ora concorrem, ora cooperam na construção da oferta de determinado produto ou serviço. Os agentes que ocupam a posição dominante agem no sentido de manter ou melhorar sua posição na estrutura do campo, disputando os diferentes capitais disponíveis no espaço em questão. No caso do mercado de capital de risco, além das empresas privadas que atuam diretamente no mercado existem as organizações estatais ligadas à indústria.

\section{Desenvolvimento do Capital de Risco no Brasil}

Segundo Macarini (2008), na segunda década de 1960, sob o regime militar, a política econômica liderada pelo economista Delfim Netto incentivou o fortalecimento do mercado financeiro, por meio de incentivos à criação de bancos de investimento e desenvolvimento do mercado de capitais. Os bancos de investimentos foram os primeiros a desempenhar o papel de intermediários financeiros e operarem segundo a lógica que, posteriormente, iria se tornar especialidade das gestoras PE. $\mathrm{O}$ segmento $\mathrm{VC}$ surgiu na mesma década. No âmbito privado investidores norte americanos por meio da Adela Investment Company S.A investiam em diversos países, inclusive no Brasil (ABDI, 2011). No âmbito do Estado este segmento ganhou o apoio da instituição que iria se destacar no apoio a inovação: a Financiadora de Estudos e Projetos (FINEP).

Para Bourdieu (2005) os organismos governamentais assim como as organizações de representação de interesses ocupam posições relevantes na construção dos mercados. Assim, a análise da trajetória de agentes, individuais e coletivos, ilustra como estes e as organizações das quais participam acumulam 
capitais e contribuem nesta dinâmica. No âmbito privado as primeiras iniciativas de VC têm fortes ligações com o Estado. No prefácio do livro $O$ capital de risco no Brasil: conceito, evolução perspectivas (PAVANI, 2003), Roberto Binder, na ocasião, diretor da Associação Brasileira de Capital de Risco, atual ABVCAP (financiadora do livro com a gestora FIR Capital) destacava o papel de três executivos: "Homenagem justa seja feita, então, a Roberto Teixeira da Costa, Ary Burger e Thomas Tosta de Sá, pelo seu trabalho pioneiro e visionário." Estes três homenageados desempenharam papel chave em organizações governamentais relacionadas à indústria de capital de risco, além de suas contribuições enquanto agentes privados.

Roberto da Costa, economista pela Universidade Federal do Rio de Janeiro (UFRJ) foi o primeiro presidente da CVM (1977-1979) participando da criação daquela que controla a indústria. Em seu currículo também está a participação da estruturação do primeiro fundo VC privado (Brasilpar em 1976), que teve o BNDES como um dos principais cotista. Atua hoje tanto na esfera privada como na pública, como conselheiro de empresas como a Sul América Seguros e BNDESPar. Também ocupa a presidência da câmara de arbitragem da Bovespa e mantém ligações com o espaço acadêmico, publicando livros sobre a história do mercado financeiro brasileiro e participando de conselhos acadêmicos.

Thomas Tosta de Sá, engenheiro da PUC-RJ com mestrado em administração na Universidade de Nova York, também presidiu a CVM (1993-1995) e atuou como sócio da Mercatto Gestão de Recursos (2001-2011). Possui uma trajetória profissional marcada por participar direta e indiretamente do mercado de capitais, na presidência do Instituto Brasileiro de Mercado de Capitais (IBMEC); na coordenação do comitê executivo do plano diretor do mercado de capitais; como diretor-conselheiro da Associação Brasileira das Companhias Abertas (ABRASCA) e conselheiro da Associação Brasileira de Venture Capital \& Private Equity (ABVCAP).

Ary Burger, terceiro homenageado, o foi, pelo protagonismo no desenvolvimento deste subcampo econômico. Falecido em 2010, Burger foi professor de economia da Universidade Federal do Rio Grande do Sul (UFRS) e fundou a Companhia de Participações em 1981, empresa que desde sua fundação se destacou entre as principais gestoras de VC no Brasil (MUNDO NETO, 2013), contando com os recursos de um grupo seleto de investidores institucionais em seus fundos: o BNDES, a FINEP, o Banco Regional de Desenvolvimento do Extremo Sul (BRDE), os principais fundos de pensão nacionais (PETROS, VALIA, FUNCEF, FAPES), o International Finance Corporation (IFC), o Inter-American Development Bank e o SEBRAE. Antes de fundar a CRP, Ary Burguer foi Secretário da Fazenda do Estado do RS, presidente do Banco Regional de Desenvolvimento do Extremo 
Sul (BRDE), do Banco de Desenvolvimento do Estado do RS S/A (BADESUL), diretor do Banco Central do Brasil e diretor financeiro do grupo Gerdau.

As trajetórias dos homenageados, em relação à indústria de capital de risco, guardam semelhanças; desde suas formações acadêmicas, passando por suas participações em grupos influenciados pela tradição econômica neoclássica; até suas passagens por órgãos estatais ligados à legislação e fiscalização da indústria. Já na esfera privada, todos atuaram como sócios de gestoras de investimentos nos anos seguintes à expansão da indústria de capital de risco. Todos contribuíram para a fundação da ABVCAP e segundo Pavani (2003), entre as instituições que fundaram a ABCR destacavam-se a Pontifícia Universidade Católica do Rio de Janeiro (PUC-RJ) e a UFRS. Atualmente percebe-se forte influência da FGV, por meio do Centro de Estudos em Private Equity e Venture Capital (GVCEPE), não apenas na formação de profissionais, mas na elaboração e difusão de estudos em capital de risco, tornando-se um dos atores mais atuantes na coleta e organização de dados sobre esta indústria.

\subsection{Composição e Contrastes da Indústria de Capital de Risco no Brasil}

A consolidação da indústria de capital de risco impulsionou a difusão de uma literatura institucional que retrata discursivamente a atuação nas vertentes de VC e PE como uma mesma indústria (LOPES; FURTADO, 2006; ABDI, 2011; SIQUEIRA; CARVALHO; GALLUCCI NETTO, 2011; ABVCAP, 2016) visando impregnar a vertente $\mathrm{PE}$ com a legitimidade associada à vertente $\mathrm{VC}$. Apesar das tentativas de ressignificar a vertente $\mathrm{PE}$, os dados da CVM não indicam que empresas financiadas via $\mathrm{PE}$ (prioritariamente envolvendo $\mathrm{F} \& \mathrm{~A}$ ) tenham, num momento anterior sido financiadas por VC, realizando o denominado (e idealizado) ciclo PE/VC, um ciclo virtuoso defendido (também) discursivamente pelas lideranças da indústria (ABDI, 2011; ABVCAP, 2016). A Tabela 1 também evidencia a discrepância entre os fundos das duas modalidades registrados na CVM em 2013 e 2017.

Comparando os dados de 2013 e 2017, constata-se que, em 4 anos, o volume de investimento na indústria cresceu $388 \%$. E, considerando o crescimento por segmento, tem-se que os fundos PE (FIPs - Fundos de Investimentos em Participações) cresceram 392\% nesse período, enquanto o VC cresceu $47 \%$. Além disso, no segmento $\mathrm{PE}$, tanto o número de firmas gestoras como o número de fundos cresceu, enquanto no segmento VC, ambos, diminuíram. 
TABELA 1: Modalidades dos fundos VC/PE, total de recursos por modalidade, número de fundos e firmas gestoras por modalidade de fundos (Julho/2013)

\begin{tabular}{|c|c|c|c|c|c|}
\hline & Modalidade & US\$ (em milhares) & $\begin{array}{c}\% \\
\text { Total } \\
\end{array}$ & $\begin{array}{l}\text { Número de } \\
\text { Fundos }\end{array}$ & $\begin{array}{c}\text { Número de Firmas } \\
\text { Gestoras }\end{array}$ \\
\hline \multirow{3}{*}{$\stackrel{n}{\frac{n}{2}}$} & FMIEEs & $436.821,46$ & 0,87 & $33(5,4 \%)$ & $\begin{array}{l}19 \text { ( } 8 \text { controlam mais } \\
\text { de } 90 \% \text { do total de } \\
\text { recursos do segmento) }\end{array}$ \\
\hline & FIPs & $49.785 .305,50$ & 99,13 & $576(94,6 \%)$ & $\begin{array}{c}62 \text { (20 controlam } 92 \% \\
\text { do total de recursos do } \\
\text { segmento) }\end{array}$ \\
\hline & FMIEEs + FIPs & $50.222 .127,01$ & 100 & $609(100 \%)$ & \\
\hline \multirow{3}{*}{$\frac{7}{\delta}$} & FMIEEs & $643.933,74$ & 0,27 & $24(2,5 \%)$ & $\begin{array}{l}17 \text { ( } 8 \text { controlam mais } \\
\text { de } 90 \% \text { do total de } \\
\text { recursos do segmento) }\end{array}$ \\
\hline & FIPs & $244.358 .249,88$ & 99,73 & $936(97,5 \%)$ & $\begin{array}{c}70 \text { (24 controlam } 92 \% \\
\text { do total de recursos do } \\
\text { segmento) }\end{array}$ \\
\hline & FMIEEs + FIPs & $245.002 .183,62$ & 100 & $960(100 \%)$ & \\
\hline
\end{tabular}

Fonte: Organizado pelos autores a partir da CVM $(2013,2017)$ e Mundo Neto (2013)

Mundo Neto (2013), ao analisar a Tabela 1, apurou que a participação dos principais agentes estatais que operam na indústria (BNDES Participações e FINEP) equivalia a quase $25 \%$ dos recursos aportados no segmento $\mathrm{VC}$.

Em se tratando de gestão privada de VC no Brasil, Fernando Reinach ganhou destaque à frente das operações da Votorantim Novos Negócios (VNN), subsidiária do grupo Votorantim. Segundo Bernardes et al. (2013), os investimentos em biotecnologia da VNN foram realizados após a contratação de Fernando Reinach, ex-Professor Titular do Instituto de Química da Universidade de São Paulo (IQ-USP) e coordenador do Projeto Genoma da Fundação de Amparo à Pesquisa do Estado de São Paulo (FAPESP), responsável pela prospecção/seleção de projetos acadêmicos que receberiam investimento.

Reinach ilustra uma conversão de capitais, no sentido de Bourdieu (2005), pois sua trajetória acadêmica e reconhecimento internacional (capital cultural e simbólico) foram convertidos para o campo econômico. Atualmente, ele também administra um fundo VC, o Pitanga Invest, considerado um fundo de grife e entre os cotistas estão Pedro Moreira Salles, cuja família possui a holding Cambuhy Investimentos e a Brasil Warrant Investimentos; Roberto Leal, controlador do grupo Natura; e a Itaúsa, gestora de investimentos da família Setúbal (FAUST, 2011). 


\subsection{O Estado como Investidor: BNDESPAR e FINEP}

Os principais provedores de recursos públicos federais para o capital de risco são o BNDES e a FINEP. Segundo Desidério (2013) o BNDES, por meio de sua subsidiaria BNDESPar, tem ampliado de forma significativa sua participação no mercado de capitais brasileiro tanto em fundos de investimentos, destinados a empresas de capital fechado, como através de participação acionária em empresas de capital aberto. Desde 2007, momento de grande expansão dos investimentos internacionais no país e crescimento do numero de administradoras de capital de risco, a BNDESPar passou a integrar o quadro de associadas da ABVCAP (VALOR ECONÔMICO, 2006).

Em FMIEEs e FIPs, a BNDESPar investe, diretamente, um montante de R $\$ 2,5$ bilhões. Este total significa uma participação de 2,18\% no total de recursos alocados na indústria. Os recursos diretos destinados ao VC totalizam $\mathrm{R} \$ 61,9$ milhões, uma participação de $2,47 \%$ do total dos recursos para o segmento, distribuídos em dois FMIEEs: o CRIATEC (R $\$ 49,9$ milhões ou $80 \%$ do fundo); e o Fundo Empreendedor Brasil (R $\$ 12$ milhões ou 10\% do fundo) (BNDES, 2013).

A Financiadora de Estudos e Projetos (FINEP) tem se voltado para o desenvolvimento do VC desde o final dos anos 1990, sendo o projeto INOVAR, do inicio dos anos 2000, uma das principais iniciativas neste sentido, cujo objetivo era fazer um diagnóstico da indústria de capital de risco no Brasil (FINEP, 2012). Atualmente a FINEP vem sendo apresentada como Agência Brasileira da Inovação.

As iniciativas da FINEP para fortalecer a indústria de capital de risco tem ocorrido em conjunto com o BNDES e com as agências de fomento à inovação tecnológica estatais. Junto à iniciativa privada, desde o inicio dos anos 2000, ainda quando a ABVCAP era ABCR (Associação Brasileira de Capital de Risco), a FINEP mantém relações visando aproximar empreendedores e os investidores. Até o final de 2012, a FINEP investia em VC, um montante de R $\$ 171,9$ milhões, alocados em fundos setoriais considerados estratégicos para o país (agronegócio, petróleo e gás natural, energia, infraestrutura, etc.) (FINEP, 2012).

Do total de recursos destinados à indústria de VC a FINEP participa com $17,18 \%$ e a BNDESPar com 6,19\%. Mundo Neto (2013), ao analisar os dados agregados da Tabela 1, apurou que a participação dos principais agentes estatais que operam na indústria (BNDES Participações e FINEP) equivale a quase $25 \%$ dos recursos aportados no segmento VC.

Apesar dos esforços do estado e das instituições-chave na valorização da vertente $\mathrm{VC}$ da indústria de capital de risco, a atuação na vertente PE domina não só quantitativamente a indústria, como também, culturalmente a partir da reprodução de um modelo percebido como referência entre os atores daquele espaço. 


\section{Origens da Dominação Cultural do PE Brasileiro: O Modelo Garantia}

Um dos principais grupos de investimento da indústria de capital de risco brasileira, seja pelo pioneirismo, seja pela perenidade, mas, principalmente, por ter se tornado referência entre os que dominam o espaço, está reunido em torno da liderança de Jorge Paulo Lemann e seus principais parceiros, Carlos Alberto Sicupira e Marcel Telles. Eles participaram de operações pioneiras no gênero PE, segundo o formato predominante nos EUA, no início de 1980. A essa época, por meio do Banco Garantia, eles adquiriram as Lojas Americanas, uma das poucas empresas listadas em bolsa de valores, na época (CORREA, 2013). Tratava-se de uma empresa que seguia a configuração da public corporation, estadunidense, com alto grau de pulverização de seus acionistas. Adquirindo ações da empresa no mercado de capitais, o grupo assumiu o controle por meio de um takeover, no estilo das gestoras pioneiras da indústria americana.

Segundo Lemann, tal tomada de decisão foi sustentada pela análise de que o valor de mercado da empresa era menor do que o valor de seus ativos, sobretudo considerando seus imóveis (FUNDAÇÃO ESTUDAR, 2014). A empresa estava subavaliada, e na pior hipótese, venderiam os ativos e ainda teriam um resultado positivo. Esta tomada de posição ilustra a lógica financeira típica dos gestores de PE: o negócio é tratado de forma extremamente racional, tratando-se da avaliação de um ativo financeiro, transformado em números que indiquem os riscos, as possibilidades de redução de custos, as possibilidades de crescimento, sempre no sentido de dominar ou estar entre os que dominam o mercado no qual atuam.

A aquisição da cervejaria Brahma, além de ilustrar o modus operandi do grupo, sustentado por sucessivos processos de F\&A, transformaria suas lideranças em exemplos emblemáticos de banqueiros que viraram empresários. Desta forma, ampliavam cada vez mais a legitimidade de sua atuação não apenas em seu espaço nativo, o financeiro, mas também no espaço organizacional. Segundo Correa (2013), a aquisição da Brahma contrariava o padrão estabelecido para a decisão de investimento, pois Lemann afirma não ter feito o dever de casa, ou seja, estudar exaustivamente o negócio, o mercado e os riscos envolvidos na transação. Sua análise focara mais no potencial do negócio do que nele em si. Ele, teria se orientado por sua pesquisa sobre as maiores cervejarias do mundo e seus respectivos controladores, em particular na América Latina. Este levantamento demonstrava que a maioria constituíra fortuna estando bem posicionados nos mercados que exploravam. A aquisição da Bhrama se revelou a primeira de uma série delas, tanto no mercado interno, como no externo, que transformariam o grupo na AB-INBEV, a maior cervejaria no mundo. 
Lemann, Sicupira, Telles e Roberto Thompson fundaram, em 1993, a primeira empresa especializada em fundos PE no país, a GP investimentos. Após a venda do Banco Garantia em 1997, para o Credit Suisse, a gestora passou a reunir aqueles que se dedicavam a prospectar novos negócios. Segundo Correa (2013), duas experiências negativas contribuíram para a gestora definir seu foco em aportes via PE: uma delas ligada à atuação via VC na empresa Submarino, que apesar de lucrativa, demandou muita dedicação da equipe da GP; e a outra ligada ao aporte na Telemar, na condição de minoritários, o que dificultou a consolidação da cultura Garantia e acelerou a saída do grupo do negócio.

A GP investimentos investiu em muitos outros negócios tornando-se um mecanismo para reter os talentos formados na casa. Conforme adquiriam experiência, os profissionais assumiam cargos de comando nos novos investimentos, sempre na posição de sócios, difundindo a cultura da meritocracia e da empresa estruturada como partnership, ou seja, todos que trabalham poderiam tornar-se sócios do negócio, pagando a aquisição de suas quotas com os resultados alcançados. A participação societária motivava aqueles que eram alçados a esta posição, uma vez que, esta seria bonificada com a distribuição de dividendos, atrelada ao bom desempenho do novo negócio. À medida que os novos sócios surgiam, os fundadores da GP viram a necessidade de transferir o controle da gestora para os novos sócios em 2010, visando garantir vazão à nova geração de sócios e reorientar a atuação dos fundadores, que criaram uma nova gestora de investimentos, a 3G Capital, voltada para aquisições de grandes corporações norte americanas.

Entre as principais características da cultura de negócio forjada por Lemann está a crença na meritocracia, onde os indivíduos são reconhecidos pelos resultados que apresentam, e membros/herdeiros das famílias dos sócios controladores são proibidos de participar das empresas do grupo, denotando a preocupação em não permitir que os negócios sejam permeados por relações orientadas pela emoção e não pela razão. A permanência no grupo e suas promoções será fruto do desempenho, do cumprimento e superação das metas estabelecidas e sob sua responsabilidade. Outro elemento da cultura de negócio de Lemann é a avaliação permanente dos resultados da equipe, o que permite tanto a ascensão como o desligamento dos indivíduos, uma vez que, aproximadamente $10 \%$ do quadro com pior desempenho era dispensado no fim de cada ano.

A maioria do pessoal que trabalhava no Garantia e depois na GP tinha a possibilidade de assumir a condição de sócio dos negócios, seja das gestoras seja das empresas investidas e que passavam a ser conduzidas de acordo com a cultura do grupo. Este ponto está fortemente relacionado à estrutura societária sustentada pelo modelo de partnership, no qual a organização era estruturada com base em participações (equity), ainda que a empresa não fosse uma empresa de capital aberto. 
Esta influência está fortemente relacionada à trajetória de Lemann, sobretudo à sua graduação em economia em Harvard. Num primeiro momento, conforme depoimento na Fundação Estudar (2014) e Correa (2013), Lemann recrutava pessoal buscando candidatos que ao mesmo tempo: tivessem origem humilde (poor), fossem espertos (smart) e tivessem desejo de ficar rico (deep desire to get rich). A identificação, treinamento e retenção de talentos é outra marca da cultura do grupo. A própria expansão dos negócios era pressionada pela necessidade de criar oportunidades para reter os talentos formados dentro da cultura do grupo. Lemann ainda defende a ideia de que é preciso conscientizar aqueles em relação ao acúmulo de riquezas, a aquisição de bens de luxo e os investimentos em negócios paralelos durante o trabalho. Segundo ele, tanto um como outro contribuiriam para enfraquecer o negócio principal, minando o foco e comprometendo o desempenho individual e do grupo como um todo. A filosofia era ter uma vida confortável, sem privações, mas sem ostentação e exibicionismo. Sobre esta questão, Telles explica:

Tudo bem que as pessoas comprem carros novos, comprem seu apartamento ou aluguem casa fora. Mas dentro do trabalho nossos cérebros pertencem à firma $\mathrm{e}$ todo nosso tempo e esforço devem ser dedicados a ela. A gestão da própria grana e a perda de tempo com isto, por mais proveitosa que possa parecer, é pensar pequeno. Muito mais importante do que operar uma reserva ou um depósito em caderneta é estar comprometendo nossa inteligência, tempo e esforço na firma. Nós como comissionados somos sócios de seu sucesso e de seu lucro (CORREA, 2013, p. 143).

$\mathrm{Na}$ fala de Telles fica evidente o extremo da lógica financeira: na visão das lideranças os novos sócios tornam-se um de seus principais ativos, para quem não custa lembrar que os primeiros são sócios de seu sucesso e de seu lucro.

O conjunto de disposições acima seria parte da ideologia/cultura do Banco Garantia, que apesar de adquirido para o suíço Credit Suisse, teve tal cultura reproduzida nas demais organizações controladas/criadas por suas lideranças: sejam gestoras financeiras, empresas investidas (que após o aporte de investimento passam pelo famoso choque de gestão promovido pelo grupo), organizações sem fins lucrativos (como as iniciativas da Ismart, Instituto Endeavor, Fundação Estudar, Fundação Brava, Fundação Lemman, etc). Por meio da 3G Investimentos, o trio passou a investir em grandes companhias estrangeiras (Anheüser Busch em 2008; Burger King em 2010; Tim Hortons em 2011; Kraft Foods e Heinz em 2013; SabMiller em 2016).

Estas incursões demonstram que a legitimidade da atuação exercida por estes atores, não se restringe ao território nacional. O grupo atraiu a parceria de 
investidores como Warren Buffet, (um congênere de Lemann, nos EUA) e de Abílio Diniz, com quem, por meio dos fundos Ocean e Innova Capital, em 2015, adquiriu a rede de padarias Benjamim, mostrando que a dominação cultural exercida pelo $\mathrm{PE}$ também pode ser observada entre as elites econômicas nacionais e internacionais. Após perder o controle do grupo Pão-de-Açúcar, Abílio Diniz também concentrou as operações da holding da família, a Península Investimentos, em PE, adquirindo participações na BRF e no Carrefour, além de reorientar as estratégias da Fazenda da Toca, produtora de orgânicos da família (POZZI, MUNDO NETO, 2017).

Em meio a toda badalação que o grupo de Lemman faz jus, como bem observa Almeida (2013) apesar do trio 3G agir segundo características atípicas dos grupos empresariais brasileiros, atuando de forma totalmente desvinculada do modelo de empresa familiar, os mesmos desfrutam de financiamentos públicos subsidiados pelo BNDES. Segundo o economista entre os dez maiores emprestadores do BNDES em 2011, na categoria indústria e varejo, constavam três empresas ligadas ao 3G; AmBev, Lojas Americanas e B2W, prática que não se restringe à Lemman, tendo outro financista brasileiro, André Esteves (BTG Pactual) também se aliado ao governo (Caixa Federal) na aquisição do banco PanAmericano. Ao levantar, o que o economista chama de ironia, ela ainda destacou a importância do papel desempenhado pelo ex-diretor de Relações Corporativas da Ambev entre 20012014, Milton Seligman (ex-Ministro da Justiça no governo de Fernando Henrique Cardoso e também ocupante de vários cargos no setor público) ao intermediar as relações da empresa com o governo e demais órgãos públicos, apontando a atuação do $3 \mathrm{G}$ como "uma aula viva sobre o funcionamento e as vantagens do capitalismo liberal" (ALMEIDA, 2013, n.p.).

\section{Considerações finais}

A análise da trajetória da construção da indústria de capital de risco no Brasil é marcada pela proximidade entre as esferas pública e privada. Foi possível identificar a relação entre indivíduos e organizações na construção de novas institucionalidades para a indústria, contribuindo para o desenvolvimento de sua cultura no sentido indicado por DiMaggio (2001), uma vez que estes atuam ora na esfera publica, ora na esfera privada, ou simultaneamente em ambas, como demonstrado nas trajetórias de Roberto Teixeira da Costa, Ary Burger e Thomas Tosta de Sá.

A vertente $\mathrm{VC}$, tanto, nacional como internacionalmente, apresenta os maiores índices de fracassos da indústria. Nesta vertente atuam, sobretudo, as agências governamentais e as gestoras novatas que, historicamente, operam com recursos governamentais. É nesse contexto, que se observa a participação direta do estado 
brasileiro como investidor de capital de risco neste segmento onde os recursos da BNDESPar e FINEP representam quase $25 \%$ do total de recursos deste segmento, indicando a importância dos aportes governamentais para esta vertente, onde os riscos são maiores e os retornos menores. No Brasil, outros bancos governamentais, como o Banco Regional de Desenvolvimento do Extremo Sul e o Banco do Nordeste do Brasil também operam como investidores de fundos de capital de risco.

Além disso, a vertente $\mathrm{VC}$, representa a absoluta minoria da indústria, donde se conclui que o ciclo virtuoso do $\mathrm{VC} / \mathrm{PE}$ idealizado como forma de legitimar o financiamento à inovação, não tem se realizado, uma vez que, os dados da CVM apontam que os financiamentos via $\mathrm{PE}$ não estão relacionados à continuidade dos investimentos previamente realizados em operações de VC. Nesta vertente (PE) predominam as grandes gestoras, nacionais e internacionais, movimentando não apenas o mercado de F\&A entre empresas, mas também contribuindo para o desenvolvimento e fortalecimento do mercado de capitais nacional, ampliando cada vez mais o número de atores (intermediários financeiros) no processo de financeirização da economia brasileira, consolidando a dominação cultural pelos fundos PE.

Em relação a tal dominação, o artigo identificou elementos que contribuíram para a consolidação de uma cultura para os negócios financiados via PE amplamente influenciada pelo estilo de gestão ultra agressivo desenvolvido por JP Lemann à frente do Banco Garantia na década de 1970, e depois transplantada para o os fundos, GP Investimentos e 3G Capital, transformando-os em máquinas de aquisições de empresas referências no mercado brasileiro (e internacional) de PE.

O trio formado por Jorge Paulo Lemann, Marcel Telles e Beto Sicupira idealizou uma estrutura empresarial fundada no conceito de partnership, sustentado pela meritocracia, avaliação periódica da equipe e cortes baseados em resultados. À época, esta foi uma inovação, não só para o mundo das finanças, mas também para mundo dos negócios em geral. Também, o surgimento do Banco Garantia nos anos 1970, representou uma inovação financeira inclusive para os nativos do espaço financeiro brasileiro, dominado por bancos estatais e grandes bancos comerciais, enquanto no espaço industrial, prevaleciam a grande empresa estatal, as subsidiárias de multinacionais e as empresas nacionais familiares (DINIZ, 2013) e não havia tradição de abertura de capital de empresa em bolsa de valores. A cultura de negócio cunhada por Lemann tem uma característica que nem todas as gestoras de PE têm: a demanda do exercício do controle visando à implantação integralmente da cartilha e do choque de gestão. Esta autonomia exigida pelas gestoras lideradas por Lemann simboliza a percepção de que financistas de vanguarda seriam os mais bem preparados para administrar os ativos. Estratégias de F\&A que resultem em demissões, ou outras medidas agressivas de valorização dos ativos, poderiam 
encontrar resistências caso o controle fosse compartilhados por outros investidores, sobretudo fundos de pensão, que encontrariam dificuldades para sustentar tais estratégias junto a suas bases.

Os capitais, no sentido de Bourdieu (2005), que conferem legitimidade à atuação de Lemman no campo econômico nacional e internacional, estariam relacionados à sua formação acadêmica, sua trajetória profissional internacional, sua rede de relações sociais e políticas e ao capital simbólico acumulado em sua carreira. A trajetória deste ator emblemático no mundo das finanças passou a dominar culturalmente o modus operandi no mercado financeiro (e no mundo dos negócios); contribuindo para o desenvolvimento de um habitus na indústria de capital de risco (e fora dela); influenciando as gerações que o sucedem ligadas aos negócios de PE, às empresas investidas ou às organizações criadas (ainda que sem fins lucrativos); e reinventando as relações entre estado, mercado e sociedade.

\title{
ACTORS, ACTIONS AND CULTURAL DOMINATION WITHIN THE SOCIAL CONSTRUCTION OF THE RISK CAPITAL INDUSTRY IN BRAZIL
}

\begin{abstract}
This article approaches the Brazilian venture capital industry through the trajectories of agents who contributed to its development. The State played an important role in regulating this industry, most notably through the creation of the Securities and Exchange Commission (CVM), the Financier of Studies and Projects (FINEP) and BNDESPar, the subsidiary of the National Bank for Economic and Social Development (BNDES). The article concludes that, although the legitimacy of this industry is linked to the financing of technological innovation by the firms that operate in the venture capital segment, those who dominate the industry prefer to invest in the private equity segment, where the return on investment is significantly higher and the risk, lower. As a result, the CVM's data indicate that venture capital financing, where uncertainty and risks are highest, falls mainly on government agencies, reproducing the prevailing ideology in the global industry.
\end{abstract}

KEYWORDS: Financialization. Investment funds. Risk capital. Economic sociology. 


\section{REFERÊNCIAS}

ABDI-AGÊNCIA BRASILEIRA DE DESENVOLVIMENTO INDUSTRIAL. A Indústria de Private Equity e Venture Capital $-2^{\circ}$ Censo Brasileiro. Brasília: Centro de Gestão e Estudos Estratégicos, 2011. 420p. Disponível em: http://hdl.handle.net/10438/8419 Acesso em: 23 Fev. 2014.

ALMEIDA, M. Por que no Brasil, Lemman precisa do BNDES? Blog do Mansueto Almeida, São Paulo, 15 Fev. 2013, n.p. Disponível em: https://mansueto.wordpress.com/ tag/livre-concorrencia/. Acesso em: 16 Jun. 2017.

APPELBAUM, E.; BATT, R. Private Equity at Work: When Wall Street Manages Main Street. Russell Sage Foundation, 2014. Disponível em: http://www.jstor.org/ stable/10.7758/9781610448185. Acesso em: 2 Jun. 2017.

ARBIX, G. Estratégias de inovação para o desenvolvimento. Tempo Social, n.22, v.2, p.167$185,2010$.

ABVCAP-ASSOCIAÇÃO BRASILEIRA DE PRIVATE EQUITY \& VENTURE CAPITAL. Consolidação de dados da indústria de private equity e venture capital no Brasil. Local: São Paulo. Associação Brasileira de Private Equity \& Venture Capital, 2016. 15 p. Disponível em: http://www.abvcap.com.br/pesquisas/estudos.aspx?c=pt-br. Acesso em: 23 Jun. 2017.

BERNARDES, R. C. et al. Ensaio sobre as virtudes do capital de risco corporativo para projetos de alta tecnologia no setor agrícola: a trajetória inovadora da Alellyx Applied Genomics e da CanaVialis. Revista de Administração da USP, v.48, n.2, p.327-340, 2013. BNDES. Banco Nacional de Desenvolvimento Econômico e Social, 2013. Disponível em: www.bndes.gov.br. Acesso em: 27 Nov 2017.

BOURDIEU, P. O campo econômico. Revista Política e Sociedade. Santa Catarina, n.4, v.6, p.15-57, 2005.

CORREA, Cristiane. Sonho Grande. Rio de Janeiro: Sextante, 2013.

DAVIS, G. F.; KIM, S. Financialization of the Economy. Annual Review of Sociology, v.41, p.203-221, 2015.

DESIDÉRIO, W. A. O estado enquanto acionista: a atuação do BNDESPar no capitalismo brasileiro contemporâneo. São Carlos, 2013. 108 f. Dissertação (Mestrado em Ciências Exatas e da Terra) - UFSCar, São Carlos, 2013.

DiMAGGiO, P. The Twenty-first Century Firm: Changing Economic Organization in International Perspective. Princeton: Princeton University Press, 2001. 
DINIZ, E. Desenvolvimento e Estado desenvolvimentista: tensões e desafios da construção de um novo modelo para o Brasil do século XXI. Rev. Sociol. Polit., v.21, n.47, p.9-20, 2013.

FAUST, A. Fundo Pitanga, capital de risco de griffe. Revista Exame. São Paulo, Jun, 2011. Disponível em: http://exame.abril.com.br/revista-exame/fundo-pitanga-capital-de-risco-degrife/. Acesso em: 12 Ago. 2017.

FINEP-FINANCIADORA DE ESTUDOS E PROJETOS. Relatório de Gestão do Exercício de 2012. Brasília: Ministério de Ciência Tecnologia e Inovação, 2013. 361p. Disponível em: http://www.finep.gov.br/images/a-finep/transparencia/relatorios/relatorios-de-gestao/2012/ relatorio_gestao_finep_2012.pdf. Acesso em: 18 Ago. 2014.

FLIGSTEIN, N. The Architecture of Markets: An Economic Sociology of Twenty-firstcentury. Princeton: Princeton University Press, 2001.

FROUD, J.; WILLIAMS, K. Private equity and the culture of value extraction. CRESC, The University of Manchester. Version 2 - February 2007. Disponível em: http://www.cresc. ac.uk/publications/documents/wp31.pdf Acesso em: 10 Ago. 2017.

FUNDAÇÃO ESTUDAR (2014). Disponível em: https://www.estudar.org.br/bate-papocom-jorge-paulo-lemann/ Acesso em: 03 Mar. 2016.

GRÜN, R. A dominação financeira no Brasil contemporâneo. Tempo Social, v.25, n.1, p. 179-213, 2013.

JENSEN M. C.; MECKLING W. H. Theory of the Firm: Managerial Behavior, Agency Costs and Ownership Structure. Journal of Financial Economics, v.3, n.4, p.305-360, 1976.

LOPES, A. B.; FURTADO, C. V. Private equity na carteira de investimentos das entidades de previdência privada. Revista de Contabilidade e Finanças, v.17, n.spe2, p.108-126, 2006.

MACARINI, J. P. Um aspecto da política econômica do milagre brasileiro: a política de mercado de capitais e a bolha especulativa 1969-1971. Estudos Econômicos, v.38, n.1, p.151-172, 2008.

MAZZUCATO, M. The Entrepreneurial State: Debunking Public vs. Private Sector Myths. United Kingdom: Anthem Press, 2013.

MUNDO NETO, M. Indústria de capital de risco no Brasil: a dinâmica do financiamento da inovação tecnológica no início do século XXI. In: XVI Congresso Brasileiro de Sociologia - A Sociologia como Artesanato Intelectual, 2013, Salvador. Anais...Salvador, 2013.

PAVANI, C. O capital de risco no Brasil: conceito, evolução perspectivas. Rio de Janeiro: E-papers Serviços Editoriais Ltda, 2003. 
POZZI, G. J.; MUNDO NETO, M. Conflitos entre a produção orgânica em grande escala e a agroecologia. Revista Interface Tecnológica, v.14, n.1, p.16, 2017.

SALTORATO, P.; BENATTI, G. O Ato Performático da Reestruturação Organizacional Sob a Ideologia de Gestão Shareholder Value. Revista Brasileira de Gestão de Negócios, v.19, n.64, p. 263-288, 2017. Disponível em: https://rbgn.fecap.br/RBGN/article/view/2875/pdf Acesso em: 13 Ago.2017.

SIQUEIRA, E. M. R.; CARVALHO, A. G. de; GALLUCCI NETTO, H. Determinantes do Sucesso dos Investimentos de Private Equity e Venture Capital no Brasil. (Determinants of Success in Private Equity-Venture Capital Investments). RBFin - Brazilian Review of Finance. Rio de Janeiro, v.9, n.2, p.190-208, 2011. Disponível em: http://bibliotecadigital. fgv.br/ojs/index.php/rbfin/article/view/2825/2223. Acesso em: 27 Nov. 2017.

USEEM, M. Investor Capitalism: How Money Managers Are Changing the Face of Corporate America. New York: Basicbooks, 1996.

VALOR ECONÔMICO. BNDES une-se ao setor privado e passa a integrar associação de capital de risco. Valor Econômico. Rio de Janeiro, 22 Nov. 2006. Disponível em: http:// noticias.uol.com.br/economia/ultnot/valor/2006/11/22/ult1913u60826.jhtm. Acesso em: 22 Nov. 2014.

Recebido em 14/08/2017.

Aprovado em 23/11/2017. 